\title{
Blockade of Interleukin-6 Receptor Alleviates Disease in Mouse Model of Scleroderma
}

\author{
Shun Kitaba, ${ }^{*}$ Hiroyuki Murota, ${ }^{*}$ Mika Terao, ${ }^{*}$ \\ Hiroaki Azukizawa, ${ }^{*}$ Fumitaka Terabe, ${ }^{\dagger}$ \\ Yoshihito Shima, ${ }^{\ddagger}$ Minoru Fujimoto, ${ }^{\dagger}$ \\ Toshio Tanaka, $^{\ddagger}$ Tetsuji Naka, $^{\dagger}$ \\ Tadamitsu Kishimoto, ${ }^{\S}$ and Ichiro Katayama* \\ From the Department of Dermatology, Course of Integrated \\ Medicine and the Department of Respiratory Medicine, Allergy \\ and Rheumatic Diseases, ${ }^{*}$ Graduate School of Medicine, Osaka \\ University, Osaka; the Laboratory for Immune Signal, ${ }^{\dagger}$ National $^{-}$ \\ Institute of Biomedical Innovation, Osaka; and the Laboratory of \\ Immune Regulation, ${ }^{\S}$ Osaka University Graduate School of \\ Frontier Biosciences, Osaka, Japan
}

Activation of fibroblasts by interleukin-6 (IL-6) is implicated in the pathogenesis of scleroderma, suggesting that the inhibition of fibroblast activation may be a promising scleroderma treatment. In this study, we used an IL-6 blocking antibody (Ab) and Il-6 knockout (II-6KO) mice to examine the role of IL-6 in the bleomycin (BLM)-induced mouse model of scleroderma. BLM was administered to $\mathrm{C} 57 \mathrm{BL} / 6$ and $\mathrm{Il}-6 \mathrm{KO}$ mice to induce dermal sclerosis. BLM-treated and control phosphate-buffered saline-treated mice were treated with anti-mouse IL-6 receptor monoclonal Ab (MR161). Disease severity was evaluated by measuring dermal thickness and skin hardness, by counting the numbers of $\alpha$-smooth muscle actin-positive cells and mast cells, and by examining the cutaneous draining lymph nodes. C57BL/6 mice with BLM induced scleroderma had elevated serum IL- 6 levels and more severe dermal sclerosis than Il-6KO mice. Weekly administration of MR16-1, but not control Ab, prevented and improved dermal sclerosis, and also attenuated swelling of the draining lymph nodes. MR16-1 suppressed $\alpha$-smooth muscle actin induction in IL-6-stimulated Il-6KO fibroblasts. Our results indicate that IL-6 contributes to BLM induced dermal sclerosis and that IL-6 receptor-specific monoclonal Ab may improve the symptoms of scleroderma by suppressing fibroblast activation. (Am J Pathol 2012, 180:165-1 16; DOI: 10.1016/j.ajpath.2011.09.013)
Patients with scleroderma frequently experience broad area skin sclerosis and internal organ involvement including pulmonary fibrosis, esophageal dysfunction, pulmonary arterial hypertension, renal crisis, and heart failure. ${ }^{1}$ These symptoms dramatically affect the prognosis for scleroderma patients. Autoaggressive immunological activation and continuous activation of fibroblasts are the key components of scleroderma, yet the mechanisms underlying these are incompletely understood.

Several lines of evidence indicate that interleukin (IL)-6 contributes to the disease process in scleroderma. Serum IL-2, IL-4, IL-6, and tumor necrosis factor $\alpha$ levels are elevated in scleroderma. ${ }^{2-6}$ Increased serum IL-6 levels are also observed in both scleroderma mouse models: the bleomycin (BLM)-induced scleroderma mouse and the type 1 tight-skin mouse $\left(T s k 1 /^{+}\right) .^{7,8}$ At the cellular level, IL-6-producing T helper type 2 clones contribute to anti-DNA topoisomerase I autoantibody, a key autoantibody in scleroderma. ${ }^{9}$ The point of action of IL-6 in scleroderma remains controversial, with some evidence suggesting the final maturation step of $B$ cells ${ }^{10}$ and/or activation of fibroblasts. ${ }^{11-13}$ Thus, although the specific function of IL-6 in the pathogenesis of scleroderma remains unclear, there is ample evidence that inhibition of IL-6-mediated signaling might be a route to better treatment for scleroderma.

In this study, we used the BLM-induced scleroderma mouse model to demonstrate the importance of IL-6 in pathogenesis of scleroderma and to evaluate the effect of anti-mouse IL-6 receptor monoclonal antibody. We have examined whether MR16-1 acts directly on dermal fibroblasts by investigating the induction of myofibroblasts in vitro. We also examined the tissue of scleroderma patients treated with tocilizumab, a humanized monoclonal antibody $(\mathrm{Ab})$ against the IL-6 receptor used to treat rheumatoid arthritis or Castleman's disease. ${ }^{14}$ Patients

Supported by the Program for Promotion of Fundamental Studies in Health Sciences of the National Institute of Biomedical Innovation.

Accepted for publication September 21, 2011.

Disclosure: T.K. holds a patent for tocilizumab. All other authors have no conflicts of interest to declare.

Address for reprint requests: Hiroyuki Murota, M.D., Ph.D., 2-2, Yamadaoka, Suita-Shi, Osaka, Japan 565-0871. E-mail: h-murota@derma.med.osaka-u. ac.jp. 
with intractable scleroderma treated with tocilizumab were previously reported to show marked amelioration of dermal sclerosis. ${ }^{15}$ Our results indicate that IL-6 induces dermal sclerosis via direct activation of dermal fibroblasts and that biomolecular targeting to suppress IL-6 might be a promising therapeutic approach for scleroderma.

\section{Materials and Methods}

\section{Dermal Fibroblast Isolation and Culture}

The dermis was collected and separated from the epidermis as described previously. ${ }^{4,16}$ Briefly, newborn wild-type and II-6 knockout (KO) mouse pups (age 2 to 4 days) were sacrificed and rinsed in $70 \%$ ethanol. The skin was excised and treated with $4 \mathrm{mg} / \mathrm{mL}$ of dispase (Gibco, Invitrogen, Paisley, UK) for 1 hour at $37^{\circ} \mathrm{C}$. The dermis was then separated from the epidermis, placed in phosphate-buffered saline (PBS) $+0.05 \%$ type- 1 collagenase (Sigma-Aldrich, St. Louis, MO), and incubated at $37^{\circ} \mathrm{C}$ for 30 minutes with vigorous agitation to prepare single cells. After filtration, cells were resuspended in Dulbecco's modified Eagle's medium $+10 \%$ fetal bovine serum and incubated at $37^{\circ} \mathrm{C}$ and $5 \% \mathrm{CO}_{2}$.

The primary II-6KO fibroblasts were passaged once or twice and used for subsequent experiments. Cells were confirmed to have the classical morphology (long spindle shape) of fibroblasts.

\section{Patients and Skin Samples}

This study included two scleroderma patients treated with tocilizumab and three scleroderma patients not treated with tocilizumab. Two scleroderma patients were treated with $8 \mathrm{mg} / \mathrm{kg}$ of tocilizumab monthly for 6 months with the permission of the Ethics Committee of Osaka University Hospital and after receipt of informed consent. Detailed patient information was described previously. ${ }^{15}$
Skin samples were obtained from patients before and after treatment. Written informed consent was obtained from all patients before skin biopsy.

\section{Immunofluorescent Staining}

Wild-type (C57BL/6) and II-6KO fibroblasts were cultured to semiconfluence in 350-mm culture plates. The cultures were fixed in $4 \%$ paraformaldehyde at room temperature for 10 minutes and permeabilized with $0.5 \%$ Triton in PBS for 5 minutes. The primary Abs used were mouse monoclonal anti- $\alpha$-smooth muscle actin Ab (1:100, $\alpha$-SMA; Dako-Cytomation, Carpinteria, CA), After 1 hour incubation, cells were stained for 30 minutes with Alexa Fluor 488 anti-mouse IgG secondary Ab to $\alpha$-SMA (Invitrogen, Carlsbad, CA) and Hoechst 33342 (Molecular Probes, Eugene, OR). Mouse $\operatorname{lgG}_{2 \mathrm{a}}$ (Dako-Cytomation, Carpinteria, CA) was used as a control for nonspecific staining.

Paraffin-embedded sections derived from scleroderma patients treated with 6 months of tocilizumab or 6 months of prednisolone, and redundant tissue from surgical specimens were deparaffinized and hydrated. Skin sections derived from patients were brought to a boil in $10 \mathrm{mmol} / \mathrm{L}$ sodium citrate buffer ( $\mathrm{pH} \mathrm{6.0)}$ and then maintained at a subboiling temperature for 10 minutes. After blocking with 5\% normal goat serum (Vector Laboratories, Burlingame, CA) in PBST, they were double-stained with mouse monoclonal anti- $\alpha$-SMA Ab (Dako-Cytomation) and rabbit monoclonal phospho-p44/42 MAPK Ab (Cell Signaling, Beverly, MA). Secondary antibodies were as follows: anti-mouse Alexa Fluor 488 for $\alpha$-SMA Ab and biotinylated anti-rabbit IgG (Vector Laboratories) plus DyLight594-conjugated Streptavidin (Jackson ImmunoResearch Laboratories, West Grove, PA) for phosphop44/42 MAPK Ab. Images of immunolabeled sections were captured with a BZ-8000 microscope (Keyence, Osaka, Japan).

Table 1. Effect of MR16-1 on BLM-Induced Dermal Sclerosis in a Prevention Model

\begin{tabular}{|c|c|c|c|c|c|c|}
\hline & \multicolumn{3}{|c|}{ Thickness (mm) } & \multicolumn{3}{|c|}{ Hardness (Arbitrary) } \\
\hline & 1st $(n=4)$ & 2nd $(n=4)$ & $3 r d(n=4)$ & 1st $(n=4)$ & 2nd $(n=4)$ & 3rd $(n=4)$ \\
\hline \multicolumn{7}{|l|}{ PBS } \\
\hline Control $\mathrm{Ab}$ & $0.137 \pm 0.016$ & $0.10 \pm 0.01$ & $0.123 \pm 0.010$ & $7.09 \pm 2.17$ & $6.14 \pm 0.72$ & $4.86 \pm 1.05$ \\
\hline $\begin{array}{l}\text { MR16-1 } \\
\text { \% Change }\end{array}$ & $0.11 \pm 0.01$ & $0.111 \pm 0.011$ & $0.122 \pm 0.013$ & $8.91 \pm 2.59$ & $6.45 \pm 1.49$ & $4.92 \pm 0.77$ \\
\hline $\begin{array}{l}\text { Each experiment } \\
\text { Mean } \pm \text { SE } \\
\text { BLM }\end{array}$ & 81.82 & $\begin{array}{c}106.33 \\
95.60 \pm 7.238\end{array}$ & 98.65 & 125.64 & $\begin{array}{c}104.91 \\
110.6 \pm 7.614\end{array}$ & 101.15 \\
\hline Control Ab & $0.33 \pm 0.04^{*}$ & $0.36 \pm 0.05^{*}$ & $0.30 \pm 0.07^{\star}$ & $24.14 \pm 5.58^{*}$ & $16.61 \pm 1.90^{\star}$ & $9.93 \pm 1.51^{*}$ \\
\hline $\begin{array}{l}\text { MR16-1 } \\
\% \text { Change }\end{array}$ & $0.22 \pm 0.03^{\dagger \neq}$ & $0.29 \pm 0.02^{\neq \S}$ & $0.16 \pm 0.03^{\dagger}$ & $15.47 \pm 4.52$ & $8.53 \pm 0.80^{\dagger}$ & $5.92 \pm 0.49^{\dagger}$ \\
\hline $\begin{array}{l}\text { Each experiment } \\
\text { Mean } \pm \text { SE }\end{array}$ & 67.09 & $\begin{array}{c}81.29 \\
66.89 \pm 8.39\end{array}$ & 52.22 & 64.08 & $\begin{array}{c}51.33 \\
58.34 \pm 3.74\end{array}$ & 59.59 \\
\hline
\end{tabular}

Values are mean \pm SD. To quantify the impact of BLM treatment, \% changes were calculated as follows: (evaluative consequences of BLM treatment/that of PBS treatment) $\times 100(\%)$

${ }^{*} P<0.01 \mathrm{PBS}+$ Control Ab versus BLM+Control Ab.

${ }^{\dagger} P<0.01 \mathrm{BLM}+$ Control Ab versus BLM+MR16-1.

${ }^{\ddagger} P<0.01 \mathrm{PBS}+\mathrm{MR} 16-1$ versus BLM+MR16-1.

$\S P<0.05$ BLM+Control Ab versus BLM+MR16-1.

HPS, high-power field 


\section{Western Blot Analysis}

Wild-type and II-6KO fibroblasts were prepared as described above and cultured to semiconfluence in 100$\mathrm{cm}^{2}$ culture plates. Before treatment, fibroblast cultures were washed twice with PBS, and culture media were replaced with low-serum $(0.1 \%$ fetal bovine serum) Dulbecco's modified Eagle's medium containing $60 \mathrm{IU} / \mathrm{mL}$ penicillin, $100 \mathrm{IU} / \mathrm{mL}$ streptomycin, and $4 \mathrm{mmol} / \mathrm{L}$ glutamine. Low-serum medium was necessary to maintain viability of primary fibroblasts overnight.

Following 12 hours incubation in low-serum medium, treatments were applied to the cultures in fresh low-serum Dulbecco's modified Eagle's medium. Semiconfluent cultures were treated with $10 \mathrm{ng} / \mathrm{mL}$ of MR16-1 or 10 $\mu \mathrm{mol} / \mathrm{L}$ of PD98058 (Calbiochem, San Diego, CA) for 3 hours, and then $10 \mathrm{ng} / \mathrm{mL}$ of recombinant mouse IL-6 (R\&D Systems, Minneapolis, MN) was added to the cultures for 24 hours. At indicated time points, culture plates were rinsed twice with ice-cold PBS, and total cell protein was collected in $500 \mu \mathrm{L}$ of lysis buffer $[50 \mathrm{mmol} / \mathrm{L}$ Tris$\mathrm{HCl}$ (pH 7.6), $150 \mathrm{mmol} / \mathrm{L} \mathrm{NaCl}, 1 \%$ deoxycholic acid, $0.1 \%$ sodium dodecyl sulfate, $1 \%$ Triton $\mathrm{X}-100,1 \mathrm{mmol} / \mathrm{L}$ sodium orthovanadate, and protease inhibitor cocktail]. Western blot analysis was performed as previously described. ${ }^{4}$ Ten micrograms of protein were fractionated on SDS-polyacrylamide gels and transferred onto PVDF membranes (Bio-Rad, Hercules, CA). Nonspecific protein binding was blocked by incubating the membranes in $5 \% \mathrm{w} / \mathrm{v}$ nonfat milk powder in TBST [50 mmol/L Tris- $\mathrm{HCl}(\mathrm{pH} 7.6)$, $150 \mathrm{mmol} / \mathrm{L} \mathrm{NaCl}$, and $0.1 \% \mathrm{v} / \mathrm{v}$ Tween-20]. The membranes were incubated with mouse monoclonal anti- $\alpha$-SMA (Dako-Cytomation) $\mathrm{Ab}$ at a dilution of 1:1000 overnight at $4^{\circ} \mathrm{C}$ or with mouse monoclonal anti- $\beta$-actin (Sigma-Aldrich) at a dilution of 1:5000 for 30 minutes at room temperature. After three 5-minute washes in TBST, membranes were incubated with horseradish peroxidase-conjugated antimouse $\mathrm{Ab}$ at a dilution of 1:10,000 for 60 minutes at room temperature. Protein bands were detected using the ECL Plus kit (GE Healthcare, Little Chalfont, UK). Western blot quantification was performed with ImageJ software $(\mathrm{NIH}$, Bethesda, MD) and used to visualize fold expression differences between these treatment groups.

\section{Mice and Induction of Skin Sclerosis}

Six-week-old female mice were used in all experiments. C57BL/6 mice were purchased from Japan Clea (Osaka, Japan). Mutant C57BL/6 mice rendered null for IL-6 were described previously ${ }^{17}$ and were purchased from the National Institute of Biomedical Innovation (Osaka, Japan). Mice were maintained in our pathogen-free animal facility. All animal care was in accordance with the institutional guidelines of Osaka University. BLM (Nippon Kayaku, Tokyo, Japan) was dissolved in PBS at a concentration of $1 \mathrm{mg} / \mathrm{mL}$ and sterilized by filtration. BLM (0.1 $\mathrm{mg} / 100 \mu \mathrm{L}$ ) was injected subcutaneously into the shaved back of the mice daily for 4 weeks with a 27-gauge needle as described by Yamamoto et al. ${ }^{7}$ Control mice received $100 \mu \mathrm{L}$ of PBS instead.

\section{RNA Isolation and Real-Time PCR}

Sections of skin lesions and the cutaneous draining lymph nodes (LNs) were removed 1 day after the final injection. Total RNA was isolated using the SV Total RNA Isolation System (Promega, Madison, WI) and reverse transcribed into complementary DNA.

IL-6 expression was measured using the Power SYBR Green PCR Master Mix (Applied Biosystems, Foster City, $\mathrm{CA}$ ) according to the manufacturer's protocol. Glyceraldehyde-3-phosphate dehydrogenase (GAPDH) was used to normalize the mRNA. Sequence-specific primers were: IL-6, sense 5'-ACACACTGGTTCTGAGGGAC-3', antisense 5'-TACCACAAGGTTGGCAGGTG-3'; GAPDH,

Table 1. Continued

\begin{tabular}{|c|c|c|c|c|c|}
\hline \multicolumn{3}{|c|}{$\alpha$-SMA-Positive Cells (Cells/HPS) } & \multicolumn{3}{|c|}{ Mast Cells (Cells/HPS) } \\
\hline 1st $(n=4)$ & $2 \mathrm{nd}(n=4)$ & $3 r d(n=4)$ & 1st $(n=4)$ & $2 \mathrm{nd}(n=4)$ & $3 r d(n=4)$ \\
\hline $\begin{array}{l}6.00 \pm 4.08 \\
5.00 \pm 1.73\end{array}$ & $\begin{array}{l}3.50 \pm 1.29 \\
4.00 \pm 1.41\end{array}$ & $\begin{array}{r}8.75 \pm 1.50 \\
10.00 \pm 4.16\end{array}$ & $\begin{array}{l}12.50 \pm 4.51 \\
11.00 \pm 1.83\end{array}$ & $\begin{array}{l}21.67 \pm 3.06 \\
17.33 \pm 6.11\end{array}$ & $\begin{array}{l}31.50 \pm 5.45 \\
29.75 \pm 3.50\end{array}$ \\
\hline 83.33 & $\begin{array}{c}114.29 \\
104.0 \pm 10.32\end{array}$ & 114.29 & 88.00 & $\begin{array}{c}80.00 \\
87.48 \pm 4.177\end{array}$ & 94.44 \\
\hline $\begin{array}{l}14.00 \pm 1.83^{*} \\
10.00 \pm 1.41\end{array}$ & $\begin{array}{r}14.50 \pm 4.93^{\star} \\
7.00 \pm 1.82^{\S}\end{array}$ & $\begin{array}{l}27.75 \pm 0.96^{*} \\
15.25 \pm 2.75^{\dagger}\end{array}$ & $\begin{array}{l}46.50 \pm 8.43^{\star} \\
20.25 \pm 4.99^{\dagger}\end{array}$ & $\begin{array}{l}35.33 \pm 5.69^{\star} \\
25.00 \pm 2.00\end{array}$ & $\begin{array}{l}67.25 \pm 5.85^{*} \\
29.50 \pm 6.19^{\dagger}\end{array}$ \\
\hline 71.43 & $\begin{array}{c}48.28 \\
58.22 \pm 6.88\end{array}$ & 54.95 & 43.55 & $\begin{array}{c}70.75 \\
52.72 \pm 9.02\end{array}$ & 43.87 \\
\hline
\end{tabular}


Table 2. Effect of MR16-1 on BLM-Induced Dermal Sclerosis in a Treatment Model

\begin{tabular}{|c|c|c|c|c|c|c|c|c|}
\hline & \multicolumn{2}{|c|}{ Thickness (mm) } & \multicolumn{2}{|c|}{ Hardness (arbitrary) } & \multicolumn{2}{|c|}{$\begin{array}{c}\alpha \text {-SMA-positive cells } \\
\text { (cells/HPS) }\end{array}$} & \multicolumn{2}{|c|}{ Mast cells (cells/HPS) } \\
\hline & 1st $(n=4)$ & 2nd $(n=3)$ & 1st $(n=4)$ & 2nd $(n=3)$ & 1st $(n=4)$ & 2nd $(n=3)$ & 1st $(n=4)$ & 2nd $(n=3)$ \\
\hline \multicolumn{9}{|l|}{ PBS } \\
\hline Control Ab & $0.14 \pm 0.02$ & $0.12 \pm 0.03$ & $4.80 \pm 0.47$ & $6.19 \pm 1.29$ & $3.75 \pm 1.50$ & $2.33 \pm 0.58$ & $13.50 \pm 1.73$ & $19.67 \pm 2.52$ \\
\hline MR16-1 & $0.12 \pm 0.01$ & $0.107 \pm 0.006$ & $4.67 \pm 0.47$ & $5.68 \pm 0.43$ & $3.33 \pm 0.56$ & $2.67 \pm 1.15$ & $15.33 \pm 1.15$ & $21.00 \pm 2.00$ \\
\hline$\%$ Changes & 83.64 & 86.49 & 97.22 & 91.78 & 88.88 & 106.78 & 113.58 & 106.78 \\
\hline \multicolumn{9}{|l|}{ BLM } \\
\hline Control Ab & $0.30 \pm 0.03^{\star}$ & $0.29 \pm 0.03^{\star}$ & $9.34 \pm 1.58^{*}$ & $9.81 \pm 1.17^{\dagger}$ & $10.00 \pm 2.58^{*}$ & $7.67 \pm 0.58^{\star}$ & $37.75 \pm 2.50^{*}$ & $54.67 \pm 8.39^{*}$ \\
\hline MR16-1 & $0.21 \pm 0.05^{\neq \|}$ & $0.18 \pm 0.03^{\S}$ & $5.46 \pm 0.62^{\pi}$ & $5.41 \pm 0.77^{\Uparrow}$ & $5.50 \pm 1.29$ ? & $4.00 \pm 1.00^{\pi}$ & $27.00 \pm 2.16$ & $37.00 \pm 6.56^{ \pm 1}$ \\
\hline$\%$ Changes & 70.00 & 62.50 & 58.46 & 55.12 & 55.00 & 52.17 & 71.52 & 67.68 \\
\hline
\end{tabular}

Mean \pm SD is presented. To quantify the impact of MR16-1treatment, \% changes were calculated as follows: (evaluative consequences of MR16-1 treatment/that of PBS treatment) $\times 100(\%)$.

${ }^{\star} P<0.01$ PBS +Control Ab versus BLM+Cont. Ab.

${ }^{\dagger} P<0.05$ PBS + Control Ab versus BLM+Cont. Ab.

$\neq P<0.05 \mathrm{BLM}+$ Control Ab versus BLM+MR16- 1 .

$\S P<0.01$ PBS+MR16-1 versus BLM+MR16-1.

" $P<0.01 \mathrm{BLM}+$ Control Ab versus BLM+MR16-1

$\| P<0.05$ PBS+MR16-1 versus BLM+MR16-1.

HPS, high-power field.

sense 5'-TGTCATCATACTTGGCAGGTTTCT-3', antisense 5'-CATGGCCTTCCGTGTTCCTA-3'. Real-time PCR (40 cycles of denaturing at $92^{\circ} \mathrm{C}$ for 15 seconds and annealing at $60^{\circ} \mathrm{C}$ for 60 seconds) was run on an $A B I 7000$ Prism Detection System (Applied Biosystems).

\section{Mouse IL-6 Receptor-Specific Monoclonal Antibody Treatment}

Rat anti-mouse IL-6 receptor monoclonal Ab (clone MR16-1, rat lg $G_{1}$ ) described previously ${ }^{18}$ was provided by Chugai Pharmaceutical (Shizuoka, Japan). Purified rat lgG (isotype-matched control Ab) (Cappel, MP Biomedicals, Solon, $\mathrm{OH}$ ) was administered as a control. Preventive and therapeutic administration methods are discussed later. Percentage to control values were calculated as follows: (mean actual value/mean control value) $\times 100$.

\section{Enzyme-Linked Immunosorbent Assay of IL-6 Levels in Sera and Conditioned Media}

Serum samples were obtained from mice injected with BLM or PBS for 28 days. Conditioned media were obtained from cultured primary dermal fibroblasts of wild-type and II-6KO mice after 24 hours. Serum and conditioned media IL-6 level was measured by enzyme-linked immunosorbent assay using a commercial kit (R\&D Systems, Minneapolis, $\mathrm{MN}$ ) with a detection limit of $7.8 \mathrm{pg} / \mathrm{mL}$.

\section{Vesmeter Measurements}

Skin hardness was measured using a Vesmeter. ${ }^{19}$ Mice were sacrificed 1 day after the final injection. Skin hardness was measured three times at the injection area, avoiding the backbone of the mouse. Skin hardness was expressed as the area of the depression caused by the

Table 3. Attenuated BLM-Induced Dermal Sclerosis in Il-GKO Mice

\begin{tabular}{|c|c|c|c|c|c|c|c|c|}
\hline & \multicolumn{2}{|c|}{ Thickness (mm) } & \multicolumn{2}{|c|}{ Hardness (arbitrary) } & \multicolumn{2}{|c|}{$\begin{array}{c}\alpha \text {-SMA-positive cells } \\
\text { (cells/HPS) }\end{array}$} & \multicolumn{2}{|c|}{ Mast cells (cells/HPS) } \\
\hline & 1 st $(n=4)$ & 2nd $(n=3)$ & 1 st $(n=4)$ & 2nd $(n=3)$ & 1 st $(n=4)$ & 2nd $(n=3)$ & 1st $(n=4)$ & 2nd $(n=3)$ \\
\hline \multicolumn{9}{|l|}{ WT } \\
\hline PBS & $0.112 \pm 0.013$ & $0.14 \pm 0.04$ & $4.91 \pm 0.38$ & $5.46 \pm 0.93$ & $4.75 \pm 1.50$ & $8.00 \pm 2.00$ & $18.00 \pm 3.16$ & $28.33 \pm 4.51$ \\
\hline BLM & $0.32 \pm 0.02^{*}$ & $0.29 \pm 0.06^{\dagger}$ & $12.38 \pm 0.81^{*}$ & $9.69 \pm 0.51^{*}$ & $19.75 \pm 5.74^{*}$ & $23.33 \pm 6.11^{*}$ & $40.25 \pm 2.22^{\star}$ & $63.33 \pm 9.87^{\star}$ \\
\hline \% Change & 282.85 & 203.13 & 251.99 & 177.28 & 415.79 & 291.67 & 223.61 & 223.53 \\
\hline \multicolumn{9}{|l|}{$11-6$} \\
\hline PBS & $0.111 \pm 0.010$ & $0.12 \pm 0.01$ & $5.37 \pm 0.48$ & $5.12 \pm 0.71$ & $4.00 \pm 1.41$ & $6.67 \pm 2.52$ & $17.75 \pm 2.5$ & $29.5 \pm 0.71$ \\
\hline BLM & $0.22 \pm 0.03^{\neq \S}$ & $0.17 \pm 0.03^{\ddagger}$ & $7.14 \pm 0.96^{ \pm \uparrow}$ & $5.85 \pm 0.21^{\ddagger}$ & $9.50 \pm 4.43^{\|}$ & $13.00 \pm 1.73^{\|}$ & $22.75 \pm 4.79^{\ddagger}$ & $34.00 \pm 7.00 \|$ \\
\hline$\%$ Change & 195.71 & 133.81 & 132.87 & 114.21 & 237.50 & 195.00 & 128.17 & 115.25 \\
\hline
\end{tabular}

Mean \pm SD was presented. To quantify the impact of BLM treatment, \% changes were calculated as follows: (evaluative consequences of BLM treatment/that of PBS treatment) $\times 100(\%)$.

${ }^{\star} P<0.01$ WT with PBS versus WT with BLM.

${ }^{\dagger} P<0.05$ WT with PBS versus WT with BLM

$\ddagger P<0.01$ WT with BLM versus II-6KO with BLM.

$\$ P<0.011 /-6 K O$ with PBS versus II-6KO with BLM.

" $P<0.05 \|-6 K O$ with PBS versus $\|-6 K O$ with BLM.

$\| P<0.05$ WT with BLM versus II-6KO with BLM.

HPS, high-power field; WT, wild-type. 
Table 4. Number of Lymph Node Cells in the Scleroderma Mouse Model

\begin{tabular}{|c|c|c|c|c|c|c|}
\hline & \multicolumn{3}{|c|}{ 1st experiment (total number/lymph node, $\times 10^{7}$ ) } & \multicolumn{3}{|c|}{ 2nd experiment (total number/lymph node, $\times 10^{6}$ ) } \\
\hline & PBS & BLM & $\%$ Change & PBS & BLM & $\%$ Change \\
\hline \multirow{3}{*}{$\begin{array}{l}\text { WT } \\
\text { Control Ab } \\
\text { MR16-1 } \\
\text { II-6KO } \\
\text { WT } \\
\text { II-6KO }\end{array}$} & & & & & & \\
\hline & $\begin{array}{l}0.97 \pm 0.21(n=3) \\
0.76 \pm 0.02(n=3)\end{array}$ & $\begin{array}{l}2.17 \pm 0.31^{*}(n=3) \\
0.80 \pm 0.12^{\dagger}(n=3)\end{array}$ & $\begin{array}{l}222.61 \\
105.29\end{array}$ & $\begin{array}{l}1.90 \pm 0.41(n=4) \\
1.85 \pm 0.18(n=4)\end{array}$ & $\begin{array}{l}3.55 \pm 0.21^{*}(n=4) \\
1.85 \pm 0.34^{\dagger}\left(\begin{array}{l}n=4 \\
n=4\end{array}\right)\end{array}$ & $\begin{array}{r}186.73 \\
99.84\end{array}$ \\
\hline & $\begin{array}{l}0.81 \pm 0.18(n=3) \\
0.66 \pm 0.26(n=3)\end{array}$ & $\begin{array}{l}1.53 \pm 0.40^{\ddagger}\left(\begin{array}{l}n=3 \\
0.54 \pm 0.09^{\S}(n=3) \\
n=3\end{array}\right)\end{array}$ & $\begin{array}{r}190.03 \\
82.73\end{array}$ & $\begin{array}{l}2.36 \pm 0.26(n=3) \\
1.97 \pm 0.67(n=3)\end{array}$ & $\begin{array}{l}3.71 \pm 0.61^{\ddagger}(n=3) \\
2.20 \pm 0.29^{\S}(n=3)\end{array}$ & $\begin{array}{l}157.42 \\
111.51\end{array}$ \\
\hline
\end{tabular}

Mean \pm SD was presented. To quantify the impact of BLM treatment, \% changes were calculated as follows: (evaluative consequences of BLM treatment/that of PBS treatment) $\times 100(\%)$.

${ }^{*} P<0.01 \mathrm{PBS}+$ Control Ab versus BLM+Cont. Ab.

${ }^{\dagger} P<0.01 \mathrm{BLM}+$ Control $\mathrm{Ab}$ versus $\mathrm{BLM}+\mathrm{MR} 16-1$

${ }^{\ddagger} P<0.05 \mathrm{PBS}+$ Control $\mathrm{Ab}$ versus $\mathrm{BLM}+$ Cont. $\mathrm{Ab}$.

$\S P<0.05$ BLM + Control Ab versus BLM+MR16-1.

probe divided by the pressure of the indenter in a connected computer.

\section{Histopathological Analysis}

The back skin was removed 1 day after the final injection. Skin pieces were fixed with 10\% formaldehyde for 24 hours, embedded in paraffin, and sectioned at 3- $\mu \mathrm{m}$ thickness using a microtome. Sections were stained with hematoxylin and eosin (H\&E). Dermal thickness (measured from the epidermal-dermal junction to dermal-fat junction) was determined at $\times 100$ magnification at three randomly selected sites in each animal. Mast cells were identified in $3-\mu \mathrm{m}$ deparaffinized sections stained with $1 \%$ Toluidine Blue, and mast cells were counted in 10 randomly selected sites under $\times 400$ power using light microscopy.

\section{Immunohistochemical Analysis of $\alpha$-SMA}

Sections were cut and processed as described above. For immunohistochemical analysis, sections were deparaffinized by passage through xylene and graded etha- nols. Next, endogenous peroxide was blocked using 3\% $\mathrm{H}_{2} \mathrm{O}_{2}$ in methanol for 5 minutes. Slides were blocked with $2 \%$ bovine serum albumin for 10 minutes, and stained with primary $\mathrm{Ab}$ (anti- $\alpha$-SMA Ab 1:100 dilution) for 60 minutes. After washing with PBS containing $0.05 \%$ Triton, they were developed using Dako ChemMate Envision Kit/horseradish peroxidase (Dako-Cytomation) for 30 minutes, and counterstained with hematoxylin. $\alpha$-SMA-positive fibroblastic cells were counted in 10 randomly selected sites under $\times 400$ power using light microscopy.

\section{Flow Cytometric Analysis}

The skin draining LNs were assessed as a mixture to facilitate analysis. One day after the final infection, mice were sacrificed, and axillary, brachial, and inguinal LNs from each mouse were combined. Cell suspensions of LN cells were stained with antibodies against the following cell surface antigens: CD4, CD8, B220, CD11c, F4/80, and PDCA1 (BD Biosciences, San Jose, CA). Stained cells were analyzed by flow cytometry using a FACSCalibur flow cytometer (BD Biosciences).
A

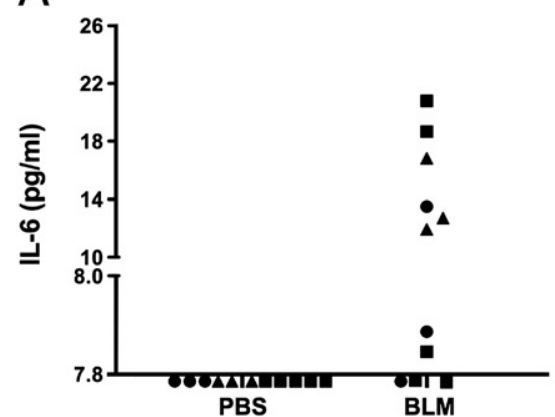

B

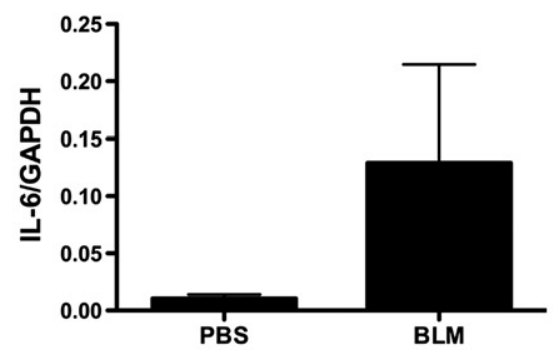

C

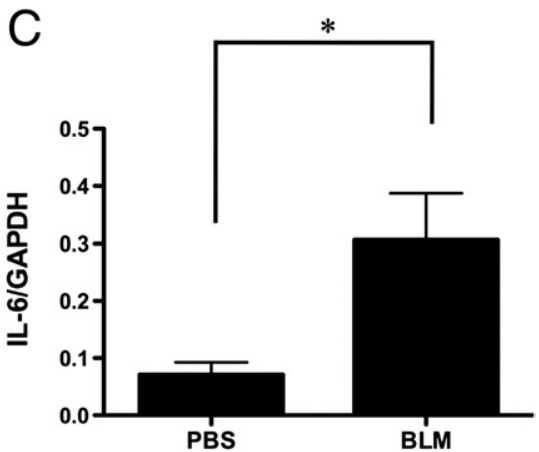

Figure 1. IL-6 production in BLM-treated C57BL/ 6 mice. C57BL/ 6 mice treated with PBS or BLM for 4 weeks. A: Serum samples were obtained from mice injected with $1 \mathrm{mg} / \mathrm{mL}$ BLM $(100 \mu \mathrm{L} /$ day, $n=11)$ or PBS $(100 \mu \mathrm{L} /$ day, $n=11)$ for 4 weeks. The data presented are from three experiments of three to five mice each for a total of 11 BLM-treated mice and 11 PBS-treated mice. Serum IL-6 level was measured by enzyme-linked immunosorbent assay using a kit with a detection limit of $7.8 \mathrm{pg} / \mathrm{mL}$ (R\&D Systems). The mice from different experiments were gave different symbols [box $(n=5)$, circle $(n=3)$, and triangles $(n=3)]$. Each symbol represents one IL- 6 measurement for a single mouse, and symbols below $7.8 \mathrm{pg} / \mathrm{mL}$ indicate mice for which IL-6 was below the limit of detection. enzyme-linked immunosorbent assays were run in duplicate for all mice, with similar results. B and C: Expression of IL-6 mRNA was measured by real-time PCR RNA was extracted from skin lesions $(\mathbf{B})$ and cutaneous draining LNs $(\mathbf{C})$ from C57BL/ 6 mice treated with PBS $(n=3)$ or BLM $(n=3)$ for 4 weeks. Data were normalized to the GAPDH internal control. Bars represent mean $\pm \mathrm{SD}$. ${ }^{*} P<0.05$, unpaired $t$-test. Data in $\mathrm{B}$ and $\mathrm{C}$ are from one of two independent experiments that gave similar results. The IL-6/GAPDH data (mean \pm SD) for skin lesions $(\mathbf{B})$ were as follows: first experiment $(n=3)$, PBS: $0.011 \pm 0.006$, BLM: $0.129 \pm 0.148(P=0.2391)$; second experiment $(n=3)$, PBS: $0.142 \pm 0.070$, BLM: $0.441 \pm 0.283(P=0.1495)$. The IL-6/GAPDH data (mean \pm SD) for cutaneous draining LNs $(\mathbf{C})$ were as follows: first experiment $(n=3)$, PBS: $0.071 \pm 0.038$, BLM: $0.306 \pm 0.141(P=0.0493)$, second experiment $(n=$ 3), PBS: $0.083 \pm 0.0 .067$, BLM: $0.430 \pm 0.175(P=0.0321)$. 
A

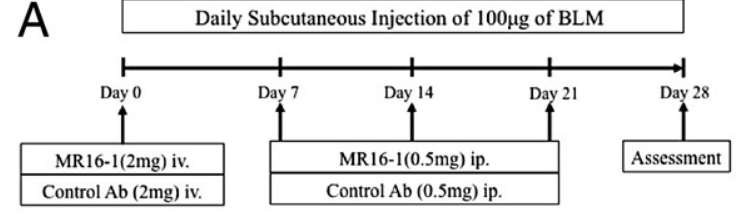

C

Control Ab

MR16-1

PBS

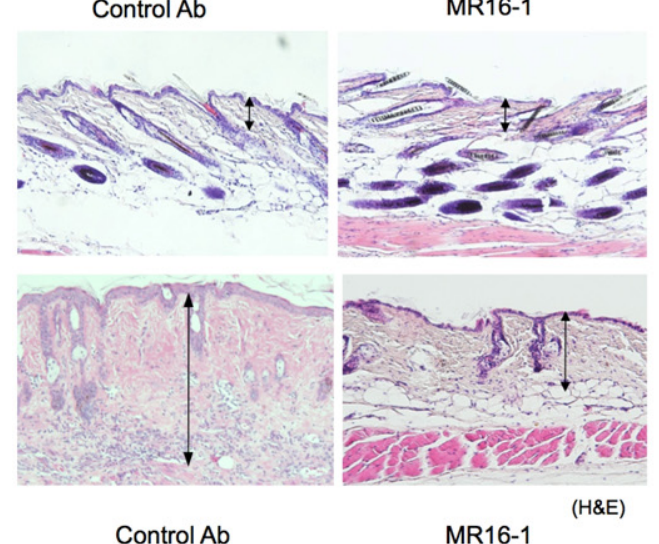

E

PBS
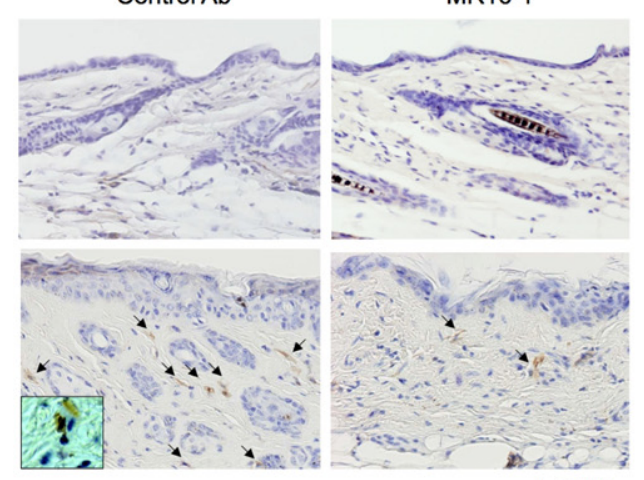

(a-SMA)

G

PBS

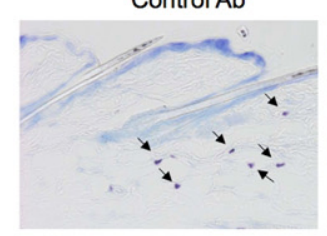

MR16-1

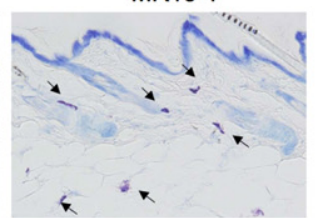

BLM
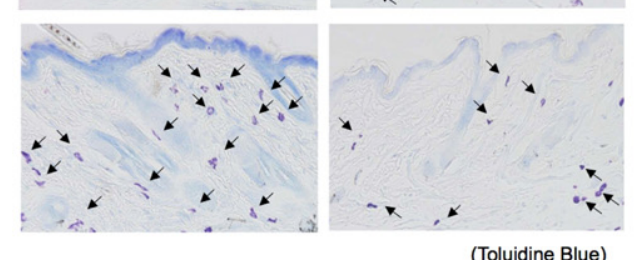
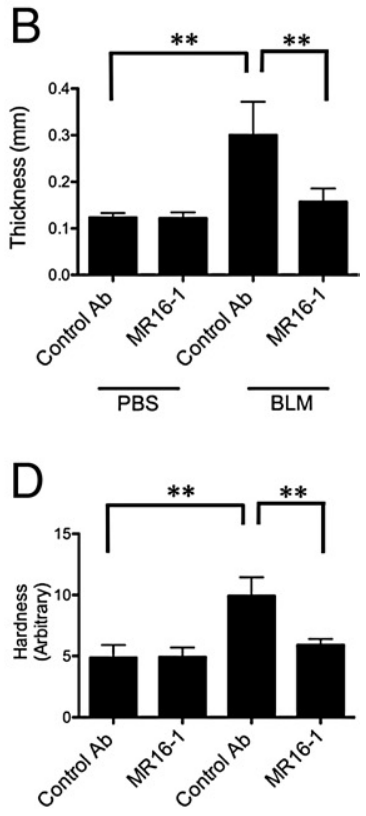

PBS $\quad \overline{B L M}$
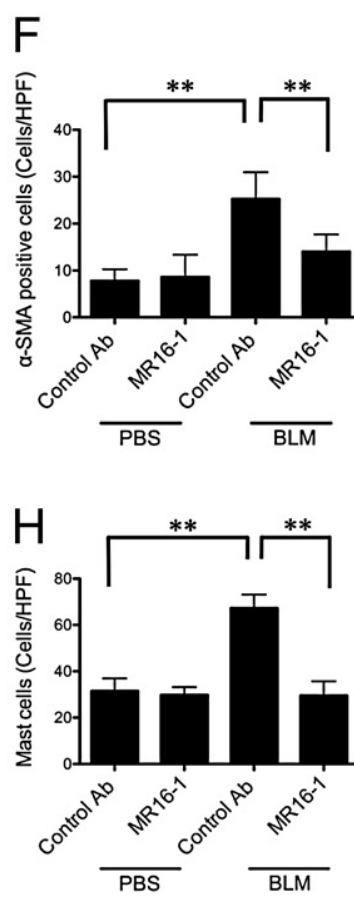

Figure 2. Effect of MR16-1 on BLM-induced dermal sclerosis in a prevention model. A: $\mathrm{Ex}$ perimental protocol for prevention of BLM-induced dermal sclerosis by administration of MR16-1 or control Ab to either PBS- or BLMtreated mice ( $n=4$ for each group). Histological and physical examination of the lesional skin was performed on the final day (day 28) of the protocol. B: Measurements of dermal thickness ( $n=4$ for each group). C: H\&E staining of specimens derived from PBS-, or BLM-injected mice treated with MR16-1 or control Ab (original magnification, $\times 40$ ). The length of each twoheaded arrow indicates the measurement region of dermal thickness. D: Skin hardness measurements obtained using a Vesmeter ( $n=4$ for each group). E: Immunohistochemical staining for $\alpha$-SMA. Arrows indicate $\alpha$-SMA-positive fibroblasts (original magnification, $\times 100$ ). Inset photo shows higher magnification $(\times 200)$ of $\alpha$-SMA-positive fibroblasts. F: The number of $\alpha$-SMA-positive fibroblasts per high-power field (HPF, $\times 400$ ) was determined by observation of 10 random grids. The value graphed is the average of the observation of 10 grids for each of the four mice in the group. G: Results of Toluidine Blue staining. Arrows indicate the metachromatically stained mast cells (original magnification, $\times 100)$. H: The number of mast cells per HPF $(\times 400)$ was determined by observation of 10 random grids. The value graphed is the average of the observation of 10 grids for each of the four mice in the group. $\mathbf{C}, \mathbf{D}, \mathbf{F}$, and $\mathbf{H}$ : Bars represent mean $\pm \mathrm{SD} .{ }^{*} P<0.05,{ }^{* *} P<0.01$ one-way analysis of variance and Bonferroni post hoc multiple comparison. Data presented are from the third of three independent experiments with similar results presented in Table 1 .

\section{Computation Methods and Statistical Analysis}

All data except change ratios are expressed as mean values \pm standard deviations (SDs). To quantify the impact of MR16-1-and BLM treatment, change ratios (\%) are calculated for single experiments in Table 1-4. Percent changes in Table 1 are averaged for three experiments and expressed as mean values \pm standard errors (SEs). Unpaired $t$-test was used to examine the statistical value between two variable quantities. One-way analysis of variance and the Bonferroni post hoc multiple comparison procedure were used to de- termine the level of significance between each of three or more variable quantities.

\section{Results}

\section{Elevated IL-6 in Mice with BLM-Induced Scleroderma}

We first determined the serum concentration and mRNA expression of IL-6 in the skin and cutaneous draining LNs from mice with skin fibrosis induced by subcutaneous 
BLM injection. Serum IL-6 levels were undetectable by enzyme-linked immunosorbent assay in all PBS-treated mice, and in 3 of 11 C57BL/6 mice treated with BLM. However, IL-6 was detectable, thus elevated, in 8 of 11 BLM-treated mice (Figure 1A), with a mean of $11.9 \pm 5.24$ $\mathrm{pg} / \mathrm{mL}(n=8)$. IL-6 mRNA expression showed a trend toward increased levels in the skin of mice treated with BLM that was not statistically significant (Figure 1B), and was significantly elevated $(P<0.05)$ in the cutaneous draining LNs of BLM-treated mice relative to PBS-treated mice (Figure $1 \mathrm{C}$ ). These results are consistent with a role for IL-6 in the pathogenesis of scleroderma in the BLMinduced mouse model.

\section{MR16-1 Prevents BLM-Induced Dermal Sclerosis}

We next investigated whether MR16-1, a rat anti-mouse IL-6 receptor monoclonal Ab, could ameliorate the dermal thickening and skin hardening symptoms observed in BLM-treated mice. Figure 2A shows the administration schedule of preventive intervention. Dermal thickness was significantly increased at the BLM injection site of control Ab-treated mice, but nearly normal at the PBS injection site of control Ab-, or MR16-1-treated mice. Importantly, BLM-induced dermal thickening was significantly attenuated by prophylactic administration of MR16-1 (Figure 2, B and C, Table 1).

Skin hardness in the BLM-injected group that was given MR16-1 was also significantly reduced compared to the BLM-injected group that was given the control Ab. The ameliorating effect of MR16-1 on skin hardness was relatively strong compared with the effect on dermal thickness (Figure 2, B and D, Table 1).

To further examine the effects of MR16-1 treatment, the numbers of $\alpha$-SMA-positive fibroblasts (termed myofibroblasts) (Figure 2, E and F, Table 1) and mast cells (Figure 2, $\mathrm{G}$ and $\mathrm{H}$, Table 1), both key players in sclerosis of skin lesions, were evaluated. The numbers of myofibroblasts and mast cells were significantly increased in BLM-injected mice treated with control Ab relative to PBS-injected mice treated with control Ab. In BLM-injected mice treated with MR16-1, the numbers of myofibroblasts and mast cells were decreased significantly compared to the control value (BLM-injected mice treated with control $A b$ ) (Figure 2, E to $H$, Table 1). These results suggest that treatment with MR16-1 might be effective during the fibrosing phase of scleroderma.

\section{MR16-1 Improves BLM-Induced Dermal Sclerosis}

Figure 3A shows the administration schedule of treatment intervention. As expected, the dermal thickness and skin hardness induced by BLM were diminished by therapeutic administration of MR16-1 compared with control Ab (Figure 3, B to D). The numbers of myofibroblasts and mast cells in lesional skin were also decreased by administration of MR16-1 compared with control Ab (Figure $3, \mathrm{E}$ and $\mathrm{F}$ ). Table 2 summarizes the data from two treatment intervention experiments. These results indicate that IL-6 may contribute to the pathogenesis of BLM-

\section{A}
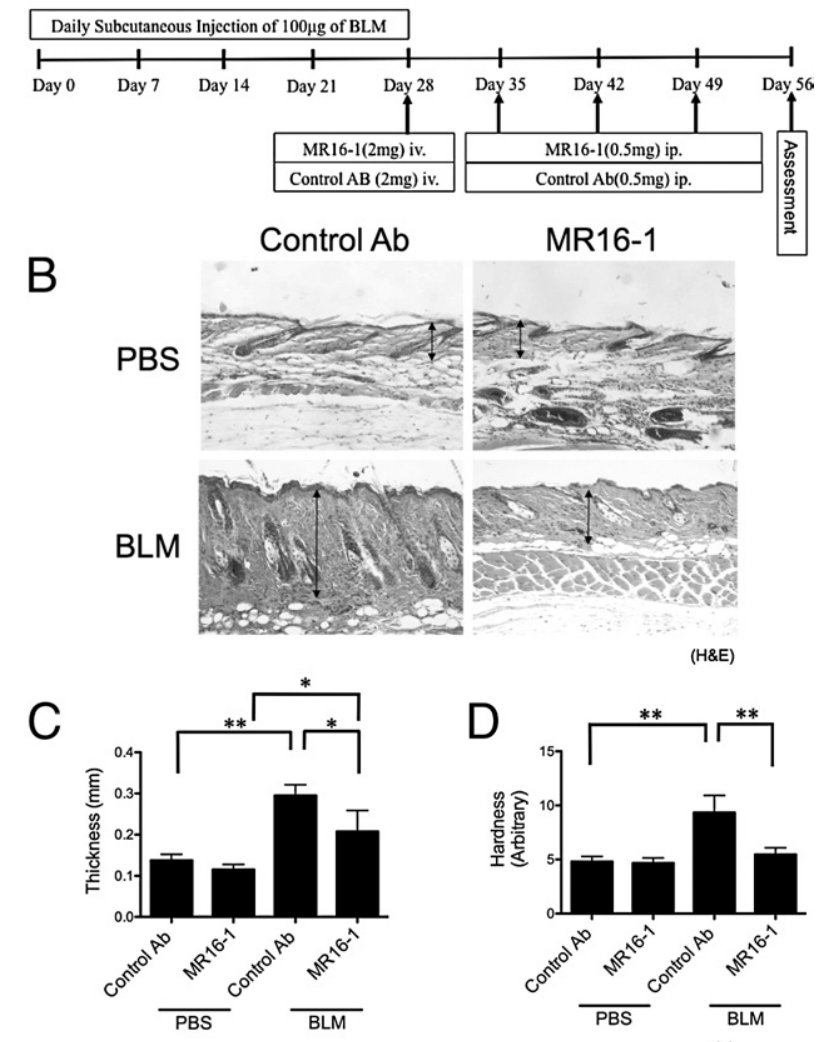

D
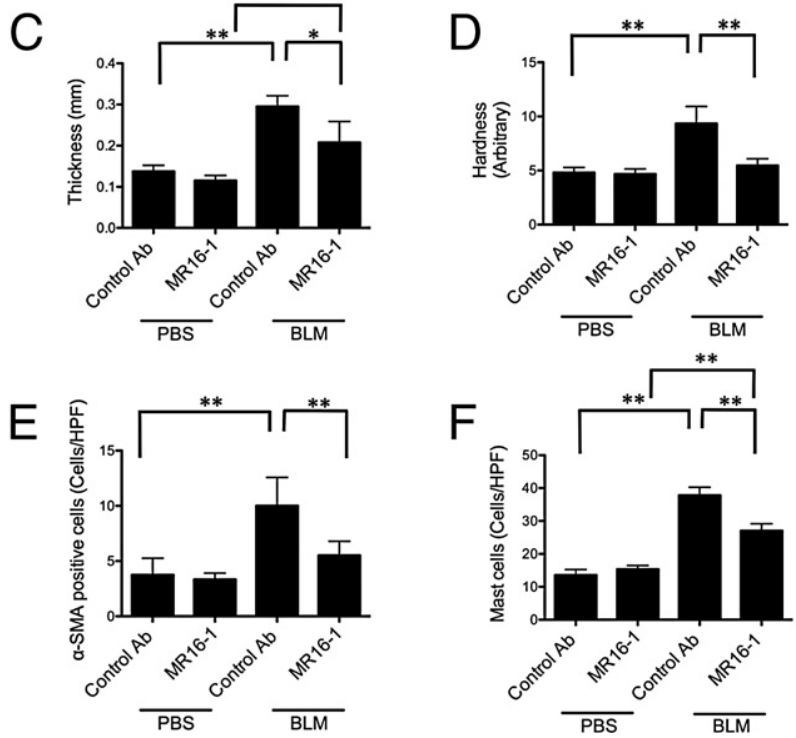

Figure 3. Effect of MR16-1 on BLM-induced dermal sclerosis in a treatment model. A: Experimental protocol for treatment of BLM-induced dermal sclerosis by administration of MR16-1 or control Ab to either PBS- or BLM-treated mice ( $n=3 \sim 4$ for each group). The effect of Ab therapy was assessed on day 56. B: H\&E staining of specimens derived from PBS- or BLM-injected mice treated with MR16-1 or control Ab (original magnification, $\times 40$ ), and measurements of dermal thickness $(\mathbf{C})$ (the measurement region of dermal thickness was indicated with the length of each two-headed arrow in B) and skin hardness (D). The number of $\alpha$-SMA-positive fibroblasts (E) and mast cells $(\mathbf{F})$ per HPF $(\times 400)$ were determined by observation of 10 random grids. The value graphed is the average of the observation of 10 grids for each of the four mice in the group. $\mathbf{C}$ to $\mathbf{F}$ : Bars represent mean $\pm \mathrm{SD} .{ }^{*} P<0.05$, ${ }^{*}{ }^{*} P<0.01$, one-way analysis of variance and Bonferroni post hoc multiple comparison. Data presented are from the first of two independent experiments with similar results. See Table 2 for data from both experiments.

induced scleroderma and that blockade of IL-6 receptor may be a novel treatment of scleroderma.

\section{IL-6 Directly Modulates $\alpha$-SMA Expression in Dermal Fibroblasts in Vitro}

We next focused on whether dermal fibroblasts are a target of IL-6. Nontreated primary dermal fibroblasts from wild-type mice already express $\alpha$-SMA, and stimulation 
A

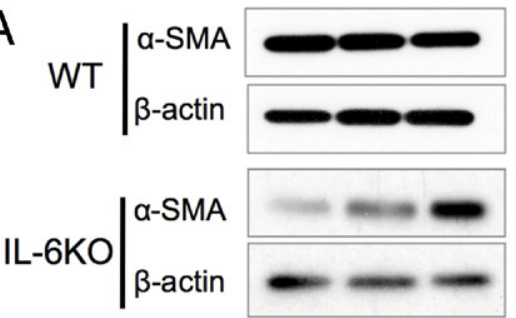

rmlL-6 (ng/ml) $0 \quad 110$
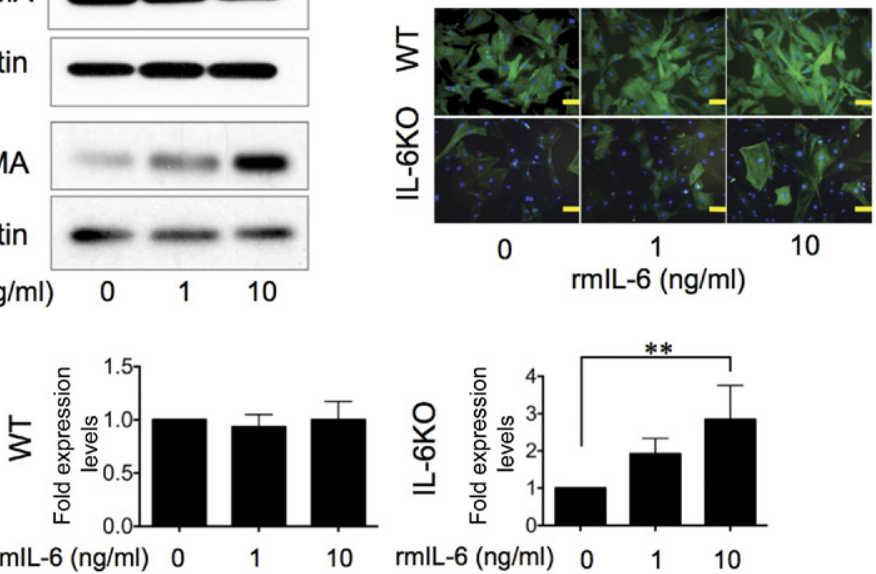

B
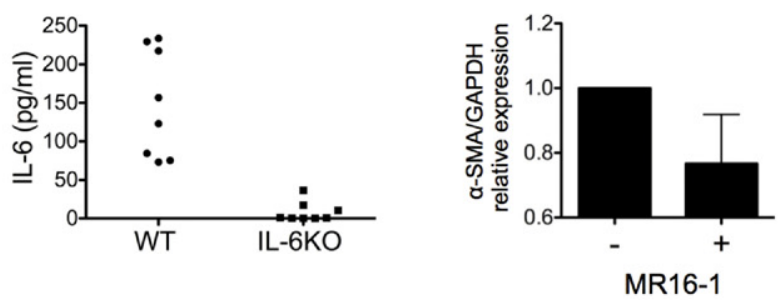

C

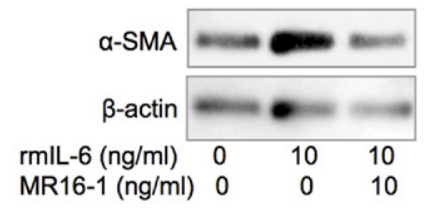

D

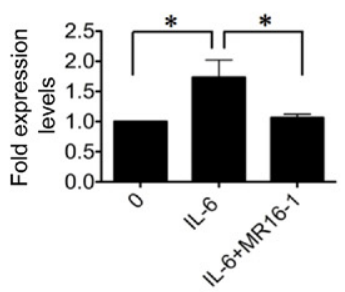

a-SMA

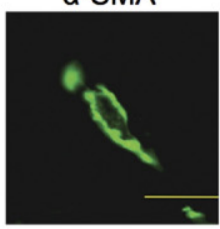

P-Erk

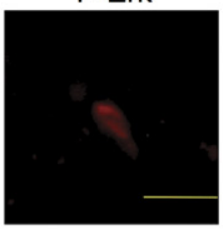

merge

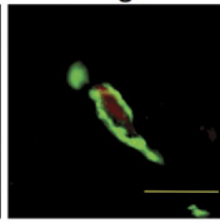

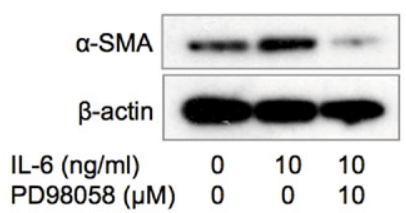

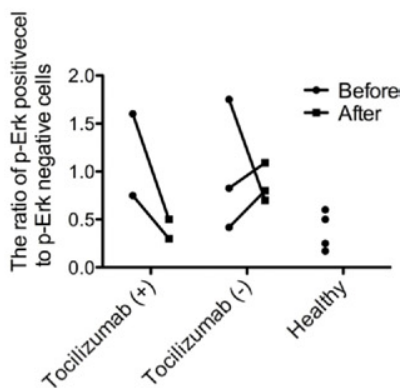

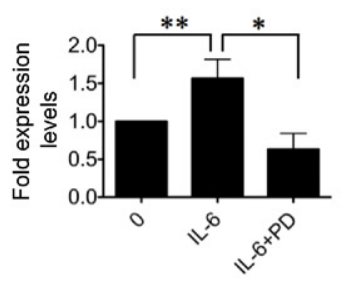

Figure 4. IL-6 induces $\alpha$-SMA protein expression in cultured $\mathrm{Il}$-6KO fibroblasts. A: $\alpha$-SMA expression following recombinant mouse Il-6 (rmIL-6) stimulation was determined by immunofluorescent staining and Western blot analysis. $\alpha$-SMA and nucleus were show in green and blue, respectively. Scale bar $=100 \mu \mathrm{m}$. $\beta$-Actin expression was used to determine fold changes in expression by densitometry. Cultured dermal fibroblasts from wild-type (WT) and $\mathrm{Il}$-6KO mice were treated with 0,1 , and $10 \mathrm{ng} / \mathrm{mL}$ rmIL- 6 for 24 hours. These experiments were repeated three times, and the results of densitometric analyses are presented as the fold change (mean $\pm \mathrm{SD}$ ) compared with control. ${ }^{* *} P<0.01$ one-way analysis of variance and Bonferroni post hoc multiple comparisons. B: $I l-6$ levels in supernatants of cultured dermal fibroblasts from WT and $I l$-GKO mice (left) after 24 hours. MR16-1 treatment decreased $\alpha$-SMA mRNA expression in cultured primary WT dermal fibroblasts (right). C: MR16-1 and ERK inhibitor, PD98058, attenuated rmIL-6-induced $\alpha$-SMA protein expression in cultured $\mathrm{Il}$-GKO fibroblasts. $\beta$-Actin expression was used to determine fold changes in expression by densitometry. These experiments were performed three times, and the results of densitometric analyses are presented as the fold change (mean $\pm \mathrm{SD}$ ) compared with control. ${ }^{* *} P<0.01,{ }^{*} P<0.05$, oneway analysis of variance and Bonferroni post hoc multiple comparisons. D: Immunofluorescent staining for phosphorylated ERK (p-ERK, red) and $\alpha$-SMA (green) in lesional skin derived from two tocilizumab-treated patients with scleroderma. A representative image of $\mathrm{p}^{-\mathrm{ERK}^{+}}$ $\alpha$-SMA ${ }^{+}$fibroblasts (original magnification, $\times 1200)$ is shown. The number of p-ERK-positive $\alpha$-SMA-positive fibroblasts per HPF $(\times 400)$ was determined by observation of 10 random grids. Scale bar $=50 \mu \mathrm{m}$. The ratio of p-ERKpositive fibroblasts was calculated as follows: the number of p-ERK ${ }^{+}, \alpha$-SMA ${ }^{+}$fibroblasts/the number of $\mathrm{p}-\mathrm{ERK}^{-}, \alpha-\mathrm{SMA}^{+}$fibroblasts. with exogenous recombinant mouse IL-6 (rmIL-6) did not alter $\alpha$-SMA expression (Figure 4A). Further, highly expressed levels of endogenous IL-6 from nontreated cultured primary wild-type dermal fibroblasts and decreased levels of $\alpha$-SMA mRNA expression after MR16 treatment indicated that hyporesponsiveness of cultured primary wild-type dermal fibroblasts to exogenous IL-6 was presumably due to the autocrine regulation of $\alpha$-SMA by IL-6 (Figure 4B). Thus, we switched to primary II-6KO mouse-derived fibroblasts and evaluated $\alpha$-SMA expres- sion using immunofluorescent staining and Western blot analysis. Low-level expression was observed in nontreated $/ 1-6 \mathrm{KO}$ dermal fibroblasts, but stimulation with 1 or $10 \mathrm{ng} / \mathrm{mL}$ of $\mathrm{rmlL}-6$ induced $\alpha$-SMA expression in a dosedependent manner (Figure 4A). $\alpha$-SMA induction by rmlL-6 was inhibited by $10 \mathrm{ng} / \mathrm{mL}$ MR16- 1 and also by the ERK1/2 inhibitor PD98059 (Figure 4C).

These results led us to examine whether the positive effects of clinical treatment with tocilizumab might correlate with reduced numbers of ERK-activated $\alpha$-SMA-pos- 
itive dermal fibroblasts in lesional skin of scleroderma patients. The number of Erk-activated $\alpha$-SMA-positive cells in lesional skin in scleroderma patients treated with tocilizumab for 6 months was reduced to a similar level as in healthy skin, whereas the number in scleroderma patients treated with $10 \mathrm{mg} /$ day of prednisolone for 6 months without tocilizumab was diminished in one patient and increased in two patients (Figure 4D).

\section{Attenuated BLM-Induces Dermal Sclerosis in II-6KO Mice}

To investigate the role of IL-6 in BLM-induced dermal sclerosis, II-6KO mice received subcutaneous injection of BLM or PBS for 4 weeks, and histological and physical examination of the lesional skin was performed (Figure 5A, Table 3). We found that BLM-induced dermal sclerosis in II-6KO mice was attenuated compared with that in wild-type mice. Lack of visible changes in the skin between PBS-treated II-6KO mice and PBS-treated wildtype mice indicated that IL-6 might not be involved in dermal homeostasis (Figure 5A). After 4 weeks of BLM treatment, dermal thickness and skin hardness in II-6KO mice were significantly attenuated compared to wild-type mice (Figure 5A). The numbers of $\alpha$-SMA-positive cells and mast cells in BLM-treated II-6KO mice were significantly reduced compared to BLM-treated wild-type mice (Figure 5B). Table 3 summarizes the data from two experiments. These results indicate that IL-6 is likely to play an important role in promoting the fibrogenic responses elicited by BLM treatment.

\section{Enlarged Draining LNs Are Reduced in Size by a Block of IL-6 in the Mouse Model and in a Patient with Scleroderma}

We found that cutaneous draining LNs were visibly enlarged by BLM treatment in the scleroderma model mice, but not by PBS treatment (Figure 6A, Table 4). The total $L N$ cell count per $L N$ in control Ab-treated BLM-injected mice was significantly increased compared with control Ab-treated PBS-injected mice, and decreased by administration of MR16-1 to BLM-injected mice. Although it was only from a single experiment with a small number of mice, the weight per LN also showed similar findings to the results of the total LN cell count per LN. However, no histological differences were observed between LNs from BLM- and PBS-injected control Ab-treated mice (Figure 6A). Detailed cell fractionation analysis (using cell-surface antigens CD4, CD8, B220, CD11c, F4/80, and PDCA 1 ) of cells isolated from the draining $L N s$ revealed that the ratio of $\mathrm{PDCA} 1^{+} \mathrm{CD} 11 \mathrm{c}^{+}$double-positive cells [plasmacytoid dendritic cells (pDCs)] was significantly increased in the draining LNs of prophylactically MR16-1-treated model mice (Figure 6B). Further, draining LNs were not grossly enlarged in BLM-treated II-6KO mice (Figure 6C, Table 4), consistent with weight and total cell count per LN measurements in the normal range (Figure 6C).
A
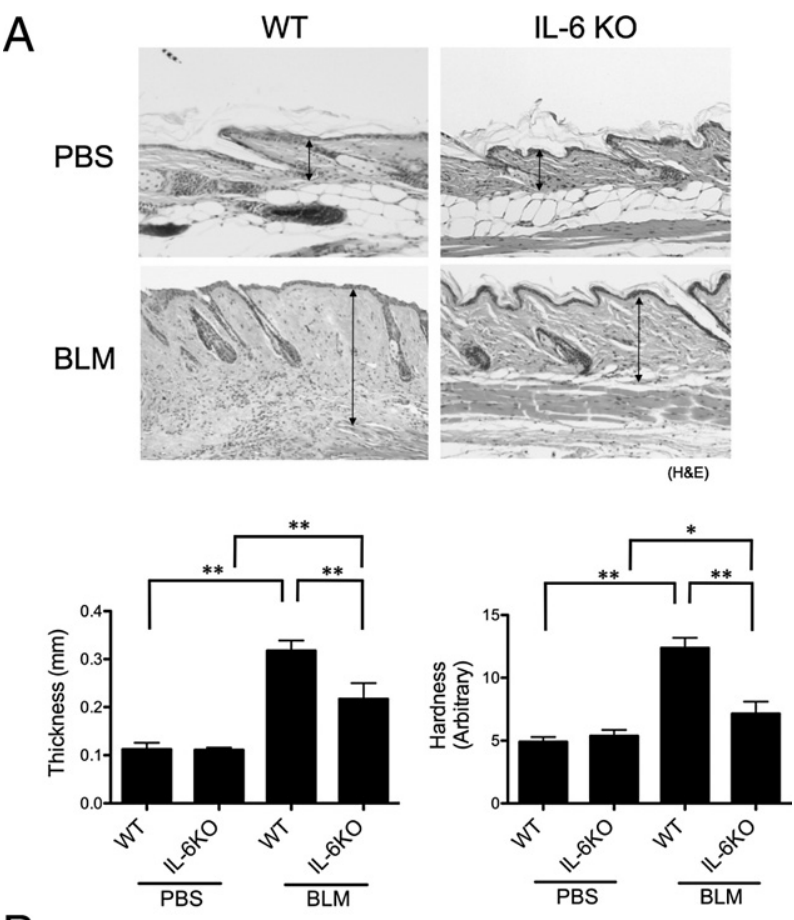

B
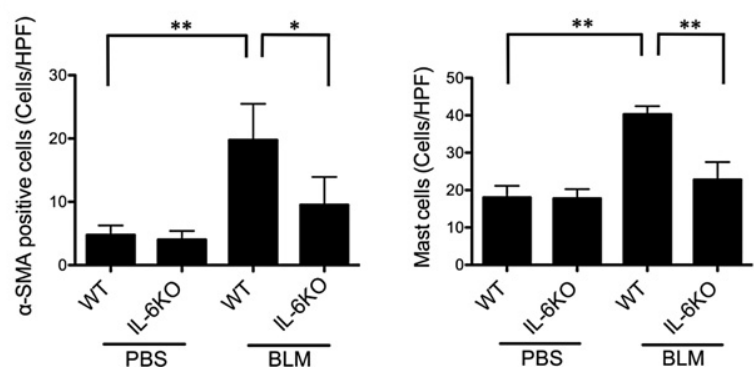

Figure 5. Attenuated BLM-induced dermal sclerosis in $I l$-GKO mice. A: H\&E staining of skin specimen derived from PBS- and BLM-treated wild-type (WT) and $\mathrm{Il}-6 \mathrm{KO}$ mice (original magnification $\times 40$ ), and measurements of dermal thickness (lower left panel) and skin hardness (lower right panel). The length of the two-headed arrows indicates the measurement region of dermal thickness. B: The number of $\alpha$-SMA-positive fibroblasts (left panel) and mast cells (right panel) per HPF $(\times 400)$ was determined by observation of 10 random grids. $\mathbf{A}$ and $\mathbf{B}$ : Bars represent mean $\pm \mathrm{SD}(n=4$ for each group). ${ }^{*} P<0.05,{ }^{* *} P<0.01$, one-way analysis of variance and Bonferroni post hoc multiple comparison. Data presented are from the first of two independent experiments that yielded similar results, and Table 3 presents data from both experiments.

We then examined whether LNs were enlarged in a patient with scleroderma, and found swelling of axillary LNs on computed tomography scan (Figure 6D), which was not detected after the administration of tocilizumab (Figure 6D).

\section{Discussion}

Our study demonstrates the critical role of IL-6 in dermal sclerosis. Blockade of IL-6 receptor with MR16-1 in the BLM-treated mice alleviates dermal sclerosis. This report also addresses outstanding problems in scleroderma pathogenesis, including the target of IL-6.

The source(s) of the elevated IL-6 in the sera of patients with scleroderma are still unclear. Several lines of 
A

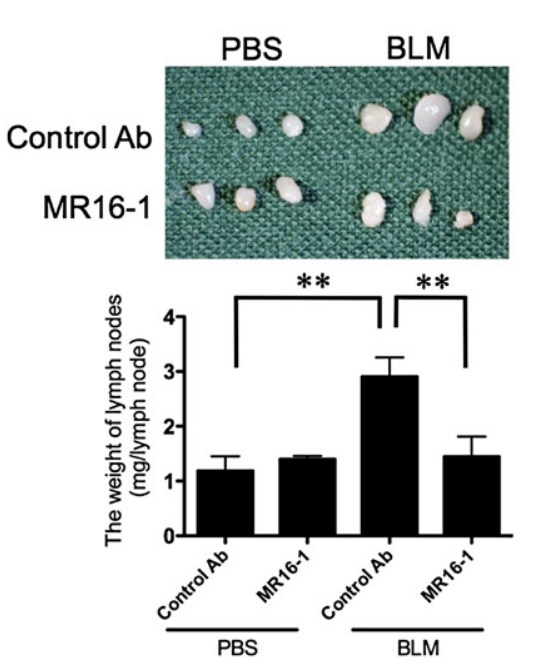

B
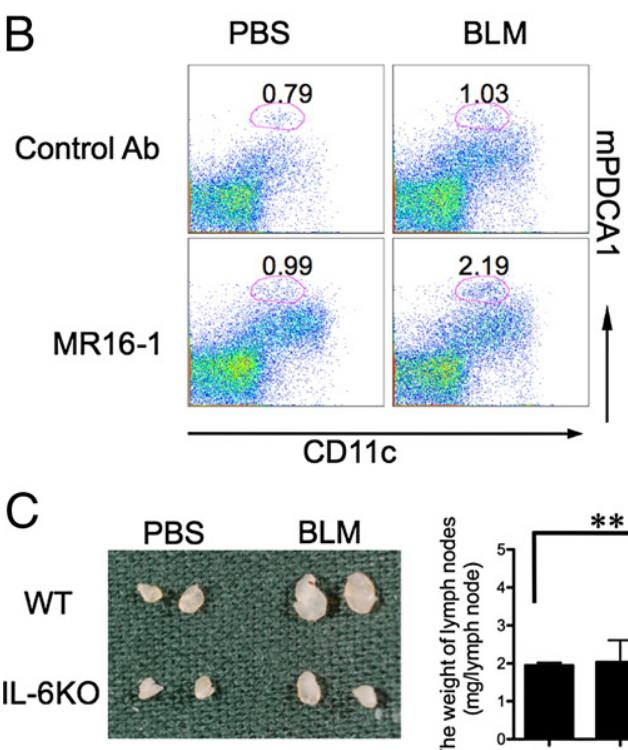
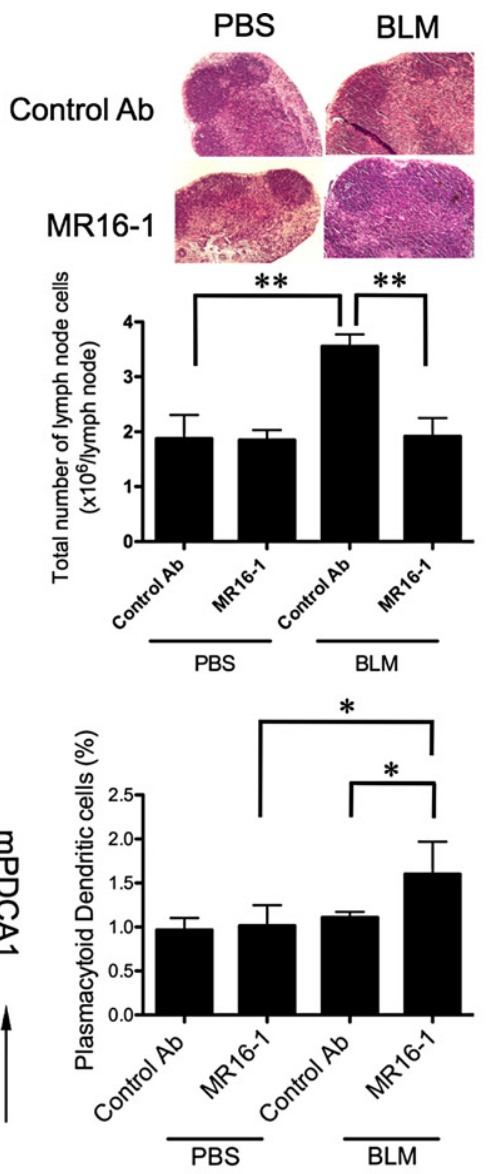

Figure 6. The size of enlarged draining LNs was reduced by administration of MR16-1 in the model mouse and in a patient with scleroderma. A: Gross appearance and H\&E staining of cutaneous draining LNs in a prevention model. The weight per LN and total cell count per LN were measured $(n=4)$. B: Cell surface marker staining of lymphocytes on cutaneous draining LNs in a prevention model. Staining results for PDCA-1 and CD11c are shown. Gated area indicates fraction of $\mathrm{pDCs}$, and the value inside the dot plot is the percentage of pDC fraction. Flow cytometric analysis was performed on pooled cutaneous draining LNs from four mice per group. C Gross appearance of cutaneous draining LNs (left panel) derived from a PBS-treated wild-type (WT) mouse, a BLM-treated WT mouse, a PBS-treated IlGKO mouse, and a BLM-treated $\mathrm{Il}$-6KO mouse. The weight per LN (center panel) and total cell count per LN (right panel) were measured ( $n=3$ for each group). D: Computed tomography scan with arrows indicating enlarged axillary LNs of the patien with scleroderma before and after administration of tocilizumab for 6 months. ${ }^{*} P<0.05$, ${ }^{\text {*** }} P<0.01$, one-way analysis of variance and Bonferroni post hoc multiple comparison. The data presented are from the second of two independent experiments that yielded similar results (see Table 4 for data from both experiments), except for the evaluation of weight of LNs, which was performed in only one of those experiments. evidence suggest peripheral blood mononuclear cells are a source. The supernatant concentration of IL-6 was reported to be statistically significantly elevated in peripheral blood mononuclear cells ${ }^{6,20,21}$ and in T-cell lines ${ }^{6}$ derived from patients with systemic sclerosis compared with healthy controls. It also has been reported that experimentally activated $\mathrm{B}$ cells might be prone to produce IL-6. ${ }^{22,23}$ Other lines of evidence implicate dermal fibroblasts as an important source of IL-6. ${ }^{13,24-28}$ In this report, although the expression of IL-6 mRNA in both lesional skin and draining LNs was increased by BLM treatment, the specific cell type producing IL-6 was not identified. Further studies are required to clarify the source(s) of IL-6.

How does secreted IL-6 contribute to the pathogenesis of scleroderma? IL-6 might modulate $\alpha$-SMA expression in dermal fibroblasts and induce myofibroblasts, which are known to produce collagen ${ }^{29}$ and induce sclerotic change. ${ }^{11,30}$ We observed IL-6 effects on $\alpha$-SMA expres-
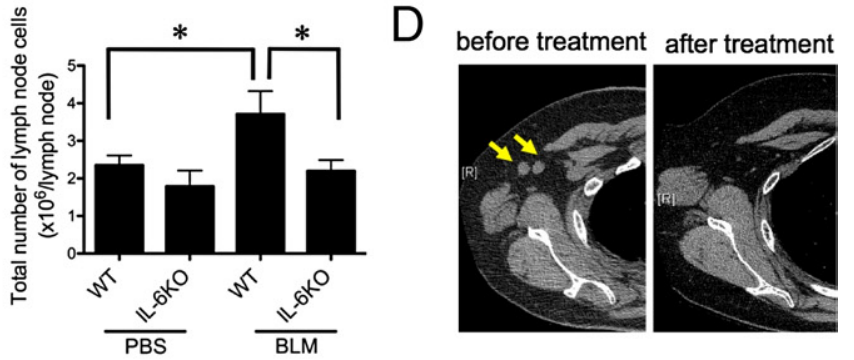

sion from II-6KO dermal fibroblasts in vitro in this study (Figure 4A). Unexpectedly, nontreated cultured wild-type dermal fibroblasts strongly expressed $\alpha$-SMA (Figure $4 \mathrm{~A})$, the expression of which was not affected by exogenous IL-6, whereas MR16-1 treatment decreased the expression of $\alpha$-SMA mRNA (Figure 4, A and B). Therefore, continuous autocrine production of IL-6 by wild-type cultured dermal fibroblasts might increase the threshold for reactivity to IL-6.

Furthermore, in both prevention and treatment protocols with MR16-1, the reduction in dermal sclerosis was accompanied by decreasing numbers of myofibroblasts, which are known as activated fibroblasts with strong fibrogenic property. The absence of myofibroblasts at the BLM injection site of II-6KO mice indicates that IL-6induced dermal sclerosis occurs via induction of myofibroblasts. Thus, we hypothesize that MR16-1 and tocilizumab have favorable effects on scleroderma via prevention of fibroblast activation. Administration of tocili- 
zumab to scleroderma patients exhibited ameliorating effects of skin sclerosis, ${ }^{15}$ and seemed to reduce the number of Erk-activated $\alpha$-SMA-positive fibroblast in lesional skin (Figure 4D). These findings were inconclusive because of the number of cases, and further studies were required.

Another finding was reduction of $L N$ swelling by MR16-1 treatment in mice in the BLM-induced model of scleroderma. We could not determine whether the LN swelling associated with BLM treatment was a cause or effect of BLM-induced skin sclerosis. Examination of the differential ratios of leukocytes, such as T cells, B cells, and macrophages, did not give any insight, as these were not altered after 4 weeks of BLM injection (data not shown). However, there was a slight, but significant, increase in the numbers of cells double-positive for PDCA-

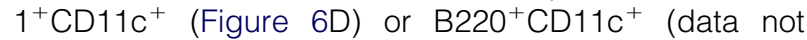
shown) in the draining LNs of MR16-1-treated mice relative to control $\mathrm{Ab}$-treated mice in the prevention model. This suggests that IL-6 might affect pDC numbers in the LNs. LN swelling is not a well-known symptom in scleroderma, and only a few articles describe LN findings in scleroderma. ${ }^{31}$ We should keep an eye on such symptoms.

Recent studies have indicated that pDCs may promote scleroderma via secretion of type 1 interferon, ${ }^{32}$ and induction of type 1 interferon was found by anti-topoisomerase antibody-containing serum, but not by anti-centromere antibody. ${ }^{32,33}$ However, other data suggest MHC class II-restricted antigen presentation by pDCs might inhibit T-cell-mediated autoimmunity via selective expansion of Ag-specific natural regulatory T cells. ${ }^{34}$ Because $\mathrm{MHC}$ class II-restricted proliferation of $\mathrm{CD} 4^{+} \mathrm{T}$ cells had been previously thought to contribute to the pathogenesis of scleroderma, ${ }^{35}$ one could speculate that an increased ratio of pDCs might prevent skin sclerosis via regulating peripheral tolerance. However, it is clear that the function of pDCs in pathogenesis of scleroderma is complex and needs further study.

The clear positive effects of IL-6 inhibition in mouse models with scleroderma indicate that further study of IL-6-secreting cells, effectors, and signaling in scleroderma holds great promise for the development of therapies for scleroderma, as well as for other diseases in which IL-6 can play a pivotal role.

\section{Acknowledgments}

We thank Prof. Junji Takeda (Osaka University) for expert comments and Dr. Toshiaki Hanafusa, Kenjyu Nishida, and Han Fu for technical assistance.

\section{References}

1. Preliminary criteria for the classification of systemic sclerosis (scleroderma). Subcommittee for scleroderma criteria of the American Rheumatism Association Diagnostic and Therapeutic Criteria Committee. Arthritis Rheum 1980, 23:581-590

2. Needleman BW, Wigley FM, Stair RW: Interleukin-1, interleukin-2, interleukin-4, interleukin-6, tumor necrosis factor alpha, and interfer- on-gamma levels in sera from patients with scleroderma. Arthritis Rheum 1992, 35:67-72

3. Hebbar M, Gillot JM, Hachulla E, Lassalle P, Hatron PY, Devulder B, Janin A: Early expression of E-selectin, tumor necrosis factor alpha, and mast cell infiltration in the salivary glands of patients with systemic sclerosis. Arthritis Rheum 1996, 39:1161-1165

4. Terao M, Murota H, Kitaba S, Katayama I: Tumor necrosis factoralpha processing inhibitor-1 inhibits skin fibrosis in a bleomycininduced murine model of scleroderma. Exp Dermatol 2009, 19:38-43

5. Murota H, Hamasaki Y, Nakashima T, Yamamoto K, Katayama I, Matsuyama T: Disruption of tumor necrosis factor receptor p55 impairs collagen turnover in experimentally induced sclerodermic skin fibroblasts. Arthritis Rheum 2003, 48:1117-1125

6. Scala E, Pallotta S, Frezzolini A, Abeni D, Barbieri C, Sampogna F, De Pita O, Puddu P, Paganelli R, Russo G: Cytokine and chemokine levels in systemic sclerosis: relationship with cutaneous and internal organ involvement. Clin Exp Immunol 2004, 138:540-546

7. Yamamoto T, Takagawa S, Katayama I, Yamazaki K, Hamazaki Y, Shinkai H, Nishioka K: Animal model of sclerotic skin. I: local injections of bleomycin induce sclerotic skin mimicking scleroderma, J Invest Dermatol 1999, 112:456-462

8. Yamamoto T, Takagawa S, Katayama I, Nishioka K: Anti-sclerotic effect of transforming growth factor-beta antibody in a mouse model of bleomycin-induced scleroderma. Clin Immunol 1999, 92:6-13

9. Kuwana M, Medsger TA Jr., Wright TM: Analysis of soluble and cell surface factors regulating anti-DNA topoisomerase I autoantibody production demonstrates synergy between Th1 and Th2 autoreactive T cells. J Immunol 2000, 164:6138-6146

10. Kishimoto T: The biology of interleukin-6. Blood 1989, 74:1-10

11. Gallucci RM, Lee EG, Tomasek JJ: IL-6 modulates alpha-smooth muscle actin expression in dermal fibroblasts from IL-6-deficient mice. J Invest Dermatol 2006, 126:561-568

12. Duncan MR, Berman B: Stimulation of collagen and glycosaminoglycan production in cultured human adult dermal fibroblasts by recombinant human interleukin 6. J Invest Dermatol 1991, 97:686-692

13. Kawaguchi $Y$, Hara M, Wright TM: Endogenous IL-1alpha from systemic sclerosis fibroblasts induces IL-6 and PDGF-A. J Clin Invest 1999, 103:1253-1260

14. Nishimoto N, Kishimoto T: Interleukin 6: from bench to bedside. Nat Clin Pract Rheumatol 2006, 2:619-626

15. Shima Y, Kuwahara Y, Murota H, Kawai M, Hirano T, Arimitsu J Narazaki M, Hagihara K, Ogata A, Katayama I, Kawase I, Kishimoto $\mathrm{T}$, Tanaka T: The skin of patients with systemic sclerosis softened during the treatment with anti-IL-6 receptor antibody tocilizumab. Rheumatology 2010, 49:2408-12

16. Gallucci RM, Sloan DK, Heck JM, Murray AR, O'Dell SJ: Interleukin 6 indirectly induces keratinocyte migration. J Invest Dermatol 2004 122:764-772

17. Kopf M, Baumann H, Freer G, Freudenberg M, Lamers M, Kishimoto T, Zinkernagel R, Bluethmann H, Kohler G: Impaired immune and acute-phase responses in interleukin-6-deficient mice. Nature 1994, 368:339-342

18. Takagi N, Mihara M, Moriya Y, Nishimoto N, Yoshizaki K, Kishimoto T, Takeda Y, Ohsugi Y: Blockage of interleukin-6 receptor ameliorates joint disease in murine collagen-induced arthritis. Arthritis Rheum 1998, 41:2117-2121

19. Kuwahara Y, Shima Y, Shirayama D, Kawai M, Hagihara K, Hirano T, Arimitsu J, Ogata A, Tanaka T, Kawase I: Quantification of hardness, elasticity and viscosity of the skin of patients with systemic sclerosis using a novel sensing device (Vesmeter): a proposal for a new outcome measurement procedure. Rheumatology (Oxford) 2008, 47: 1018-1024

20. Hasegawa M, Sato S, Ihn H, Takehara K: Enhanced production of interleukin-6 (IL-6), oncostatin M and soluble IL-6 receptor by cultured peripheral blood mononuclear cells from patients with systemic sclerosis. Rheumatology (Oxford) 1999, 38:612-617

21. Crestani B, Seta N, De Bandt M, Soler P, Rolland C, Dehoux M, Boutten A, Dombret MC, Palazzo E, Kahn MF, et al.: Interleukin 6 secretion by monocytes and alveolar macrophages in systemic sclerosis with lung involvement. Am J Respir Crit Care Med 1994, 149: 1260-1265

22. Saito E, Fujimoto M, Hasegawa M, Komura K, Hamaguchi Y, Kaburagi Y, Nagaoka T, Takehara K, Tedder TF, Sato S: CD19-dependent $B$ lymphocyte signaling thresholds influence skin fibrosis and 
autoimmunity in the tight-skin mouse. J Clin Invest 2002, 109:1453-1462

23. Matsushita T, Hasegawa M, Yanaba K, Kodera M, Takehara K, Sato S: Elevated serum BAFF levels in patients with systemic sclerosis: enhanced BAFF signaling in systemic sclerosis B lymphocytes. Arthritis Rheum 2006, 54:192-201

24. Takemura $H$, Suzuki $H$, Fujisawa $H$, Yuhara $T$, Akama T, Yamane $K$, Kashiwagi $\mathrm{H}$ : Enhanced interleukin 6 production by cultured fibroblasts from patients with systemic sclerosis in response to platelet derived growth factor. J Rheumatol 1998, 25:1534-1539

25. Kawaguchi Y, Nishimagi E, Tochimoto A, Kawamoto M, Katsumata Y, Soejima M, Kanno T, Kamatani N, Hara M: Intracellular IL-1alphabinding proteins contribute to biological functions of endogenous $\mathrm{IL}-1$ alpha in systemic sclerosis fibroblasts, Proc Natl Acad Sci U S A 2006, 103:14501-14506

26. Fukasawa C, Kawaguchi $Y$, Harigai M, Sugiura T, Takagi K, Kawamoto M, Hara M, Kamatani N: Increased CD40 expression in skin fibroblasts from patients with systemic sclerosis (SSc): role of CD40-CD154 in the phenotype of SSc fibroblasts. Eur J Immunol 2003, 33:2792-2800

27. Kadono T, Kikuchi K, Ihn H, Takehara K, Tamaki K: Increased production of interleukin 6 and interleukin 8 in scleroderma fibroblasts. J Rheumatol 1998, 25:296-301

28. Koch AE, Kronfeld-Harrington LB, Szekanecz Z, Cho MM, Haines GK, Harlow LA, Strieter RM, Kunkel SL, Massa MC, Barr WG, Jimenez SA: In situ expression of cytokines and cellular adhesion molecules in the skin of patients with systemic sclerosis. Their role in early and late disease. Pathobiology 1993, 61:239-246

29. Wynn TA: Cellular and molecular mechanisms of fibrosis. J Pathol 2008, 214:199-210

30. Kirk TZ, Mark ME, Chua CC, Chua BH, Mayes MD: Myofibroblasts from scleroderma skin synthesize elevated levels of collagen and tissue inhibitor of metalloproteinase (TIMP-1) with two forms of TIMP-1. J Biol Chem 1995, 270:3423-3428

31. Ofstad E: Scleroderma (progressive systemic sclerosis). A case involving polyneuritis and swelling of the lymph nodes. Acta Rheumatol Scand 1960, 6:65-75

32. Eloranta ML, Franck-Larsson K, Lovgren T, Kalamajski S, Ronnblom A, Rubin K, Alm GV, Ronnblom L: Type I interferon system activation and association with disease manifestations in systemic sclerosis. Ann Rheum Dis 2010, 69:1396-1402

33. Kim D, Peck A, Santer D, Patole P, Schwartz SM, Molitor JA, Arnett FC, Elkon KB: Induction of interferon-alpha by scleroderma sera containing autoantibodies to topoisomerase I: association of higher interferon-alpha activity with lung fibrosis. Arthritis Rheum 2008, 58: 2163-2173

34. Irla M, Kupfer N, Suter T, Lissilaa R, Benkhoucha M, Skupsky J, Lalive $\mathrm{PH}$, Fontana A, Reith W, Hugues S: MHC class II-restricted antigen presentation by plasmacytoid dendritic cells inhibits T cell-mediated autoimmunity. J Exp Med 2010, 207:1891-1905

35. Kuwana M, Medsger TA Jr., Wright TM: T cell proliferative response induced by DNA topoisomerase I in patients with systemic sclerosis and healthy donors. J Clin Invest 1995, 96:586-596 